\title{
Barrett's adenocarcinoma associated with acquired eventration of the diaphragm
}

\author{
Hideaki Shimoji, Hiroshi Miyazato, Atsushi Nakachi, Hirotaka Matsubara, Osamu Tamai, Tsutomu Isa, \\ Masayuki Shiraishi, Toshiomi Kusano, and Yoshiniro Muto
}

The First Department of Surgery, University of the Ryukyus, School of Medicine, Nishihara-cho, Okinawa 903-0125, Japan

\begin{abstract}
:
We report a rare case of Barrett's adenocarcinoma associated with acquired eventration of the diaphragm in a 71-year-old woman. She initially developed dysphagia and epigastric discomfort in May, 1997. On July 9, she was referred to our Department of Surgery at the Ryukyus University Hospital for thorough examination and treatment. Esophageal adenocarcinoma and eventration of the diaphragm were revealed by exhaustive examinations, including chest $\mathrm{X}$-ray, computed tomography, and magnetic resonance imaging, and proximal gastrectomy with reconstruction of jejunal interposition was performed, on August 8. Histologically, the tumor revealed that the adenocarcinoma arose from short-segment Barrett's esophagus (SSBE). It thus appears that eventration of the diaphragm may induce SSBE and Barrett's adenocarcinoma. We therefore recommend that periodic examinations of the esophagus and stomach be performed in patients with eventration of the diaphragm. Barrett's adenocarcinoma associated with acquired eventration of the diaphragm is reported. Patients with eventration of the diaphragm should undergo periodic examinations of the esophagus and stomach.
\end{abstract}

Key words: Barrett's adenocarcinoma, eventration of the diaphragm, short-segment Barrett's esophagus

\section{Introduction}

Eventration of the diaphragm [1] is a comparatively rare condition. It is reported to be found on routine chest X-rays at a frequency of once every 1400 to once over 13000 examinations [2]. Barrett's adenocarcinoma is the most common adenocarcinoma of the esophagus and has recently been reported at an increasing incidence in patients with esophageal adenocarcinoma. To

Offprint requests to: $\mathrm{H}$. Shimoji

Received for publication on Mar. 26, 1998; accepted on Aug. 11, 1998 our knowledge, no case of Barrett's adenocarcinoma associated with eventration of the diaphragm has previously been reported. We report here such a rare case and discuss the association of Barrett's esophagus and eventration of the diaphragm.

\section{Case report}

A 71-year-old woman initially presented with epigastralgia and dysphagia in early May, 1997. On July 9, she was referred to our Department of Surgery at the Ryukyus University Hospital to undergo thorough examination and treatment after presenting at a local hospital with worsening of these symptoms.

She had no contributory family history. Her past medical history revealed that she had previously undergone an appendectomy at 38 years of age, and that elevation of the left diaphragm was detected during a regular medical checkup at 44 years of age. However, she had not complained of any symptoms since then.

On physical examination at admission, her respiratory sounds were diminished over the lower left lung field, but otherwise no abnormalities were observed. Chest X-ray revealed elevated left diaphragm, while the heart had shifted toward the right (Fig. 1). Esophagography showed dilatation of the lower esophagus and partial obstruction by a mass with a ragged surface in the lower esophagus. Barium meal stagnated in the esophagus and streamed only slightly into the stomach (Fig. 2). Computed tomography (CT) and magnetic resonance imaging (MRI) revealed increased wall thickness of the abdominal esophagus through the cardia of the stomach and elevated thin diaphragm (Fig. 3). Endoscopic examination showed a large cauliflower-type tumor in the distal esophagus approximately $36 \mathrm{~cm}$ away from the incisors. The tumor occupied most of the esophageal lumen and the endoscopic fiber could not get through to the anal side of the tumor. 
Endoscopically, the oral side epithelium of the tumor demonstrated an almost normal esophageal mucosa, but it was reddish and with capillary dilatation (Fig. 4).

Biopsy specimens from the tumor and the oral side epithelium of the tumor revealed adenocarcinoma and a columnar epithelium which were positive for alcian blue $\mathrm{pH} 2.5$ ( $\mathrm{AB} \mathrm{pH}$ 2.5). Based on these findings, we suspected esophageal adenocarcinoma arising from

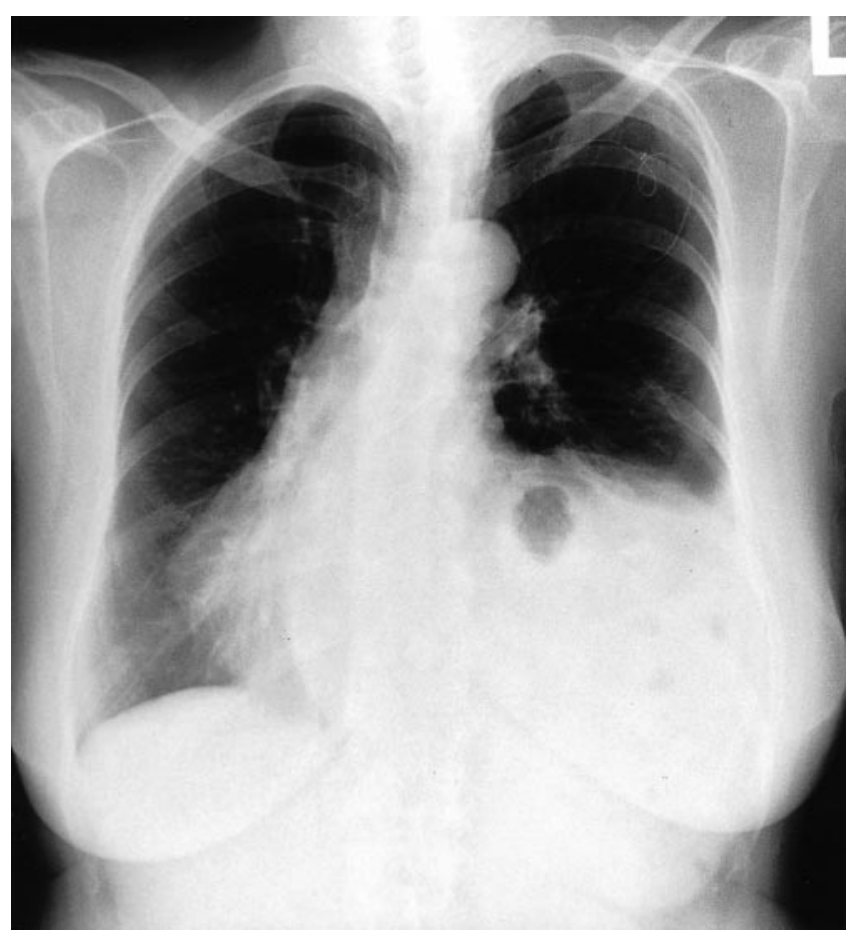

Fig. 1. Chest X-ray showing elevated left diaphragm; the mediastinum is shifted toward the right
Barrett's epithelium, and acquired eventration of the diaphragm.

On August 8, a proximal gastrectomy with reconstruction of the jejunal interposition was performed. At laparotomy, the left diaphragm was thin, relaxed, and elevated up to the thorax. The relaxed and deformed stomach extended up to the high left diaphragm, but no gastric volvulus was observed.

\section{Pathology findings}

Macroscopically, the cauliflower-type tumor extended over the esophagogastric junction, and measured $5.7 \times 5.2 \mathrm{~cm}$ (Fig. 5).

Microscopically, the oral side of the surgical specimen showed normal squamous epithelium, columnar epithelium with goblet cells, dysplastic epithelium, and well differentiated adenocarcinoma. All these tissues, except for the squamous epithelium, were positive for $\mathrm{AB} \mathrm{pH}$ 2.5 (Fig. 6). The anal side mucosa of the tumor was covered with a typical gastric mucosa without intestinal metaplasia. The gastric mucosa was not positive for $\mathrm{AB}$ pH 2.5 but was positive only for periodic acid-Schiff (PAS). The depth of cancer invasion reached to the adventitia. There was no evidence of tumor spread to the adjacent structures or metastases to the lymph nodes and distant organs.

\section{Discussion}

There are two general theories regarding the etiology of eventration of the diaphragm: the congenital and acquired theories. It is presumed that acquired

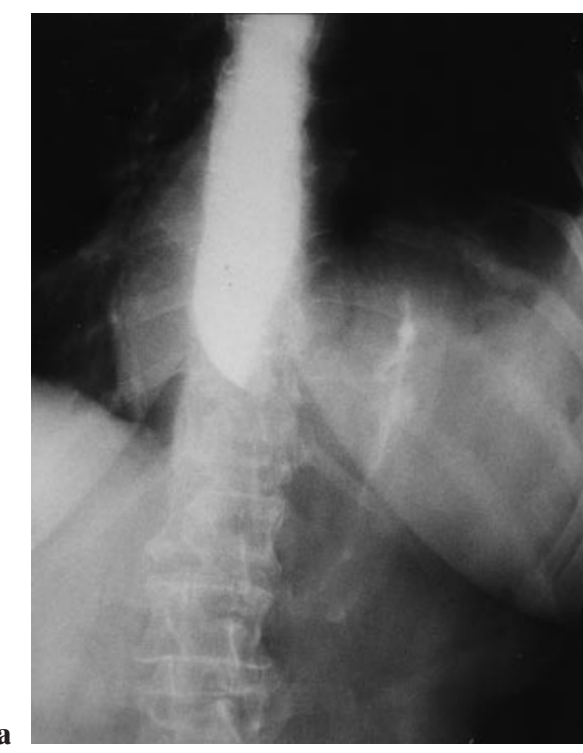

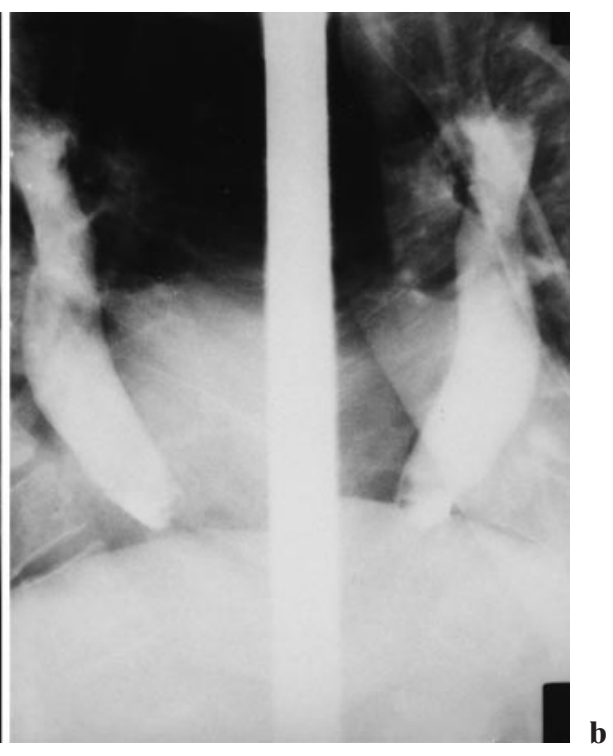

Fig. 2a,b. Esophagography shows barium meal a stagnating in the esophagus while only slightly streaming into the stomach and $\mathbf{b}$ mass with a ragged surface obstructing the lower esophagus 


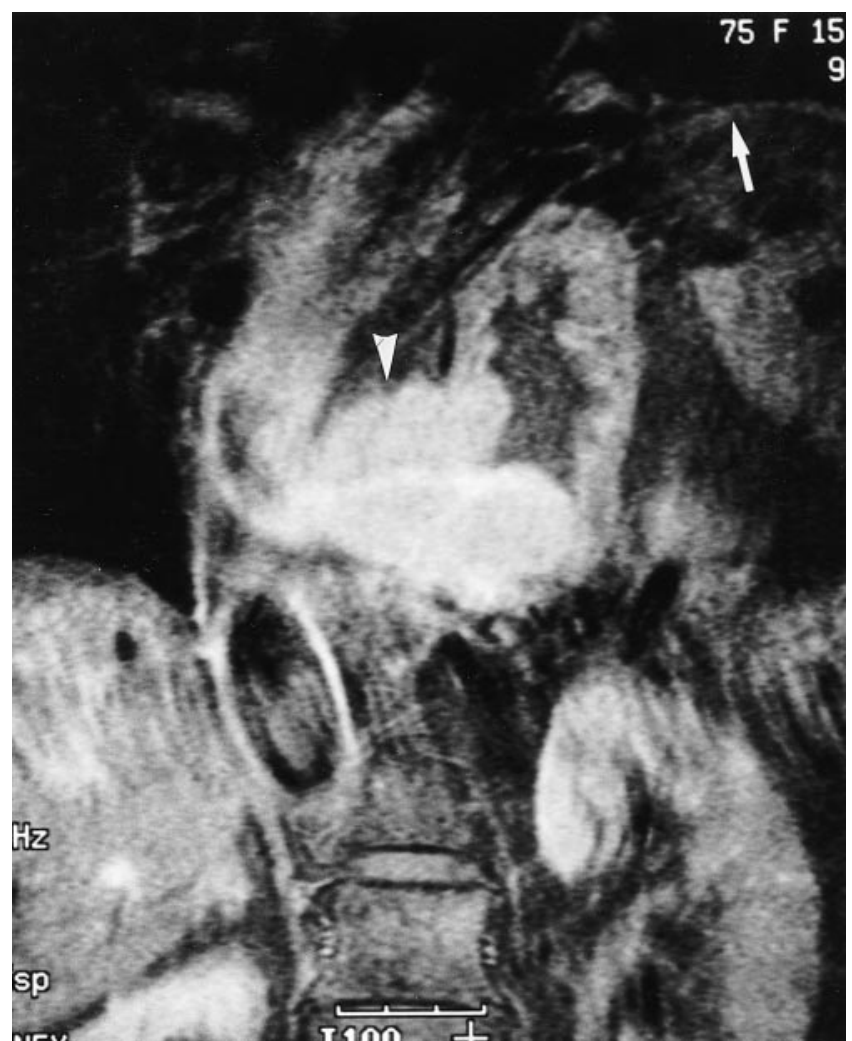

Fig. 3. T2-weighted coronal magnetic resonance image shows thin diaphragm (arrow), and thickened wall of the abdominal esophagus and the cardia (arrowhead)

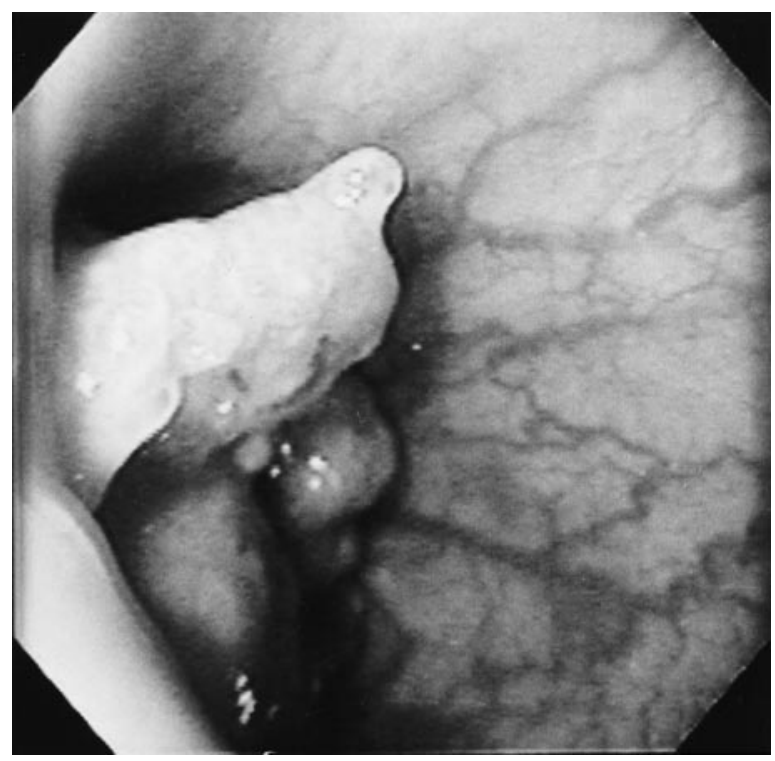

Fig. 4. Endoscopic examination showing cauliflower-type tumor and capillary dilatation of the mucosa in the lower esophagus
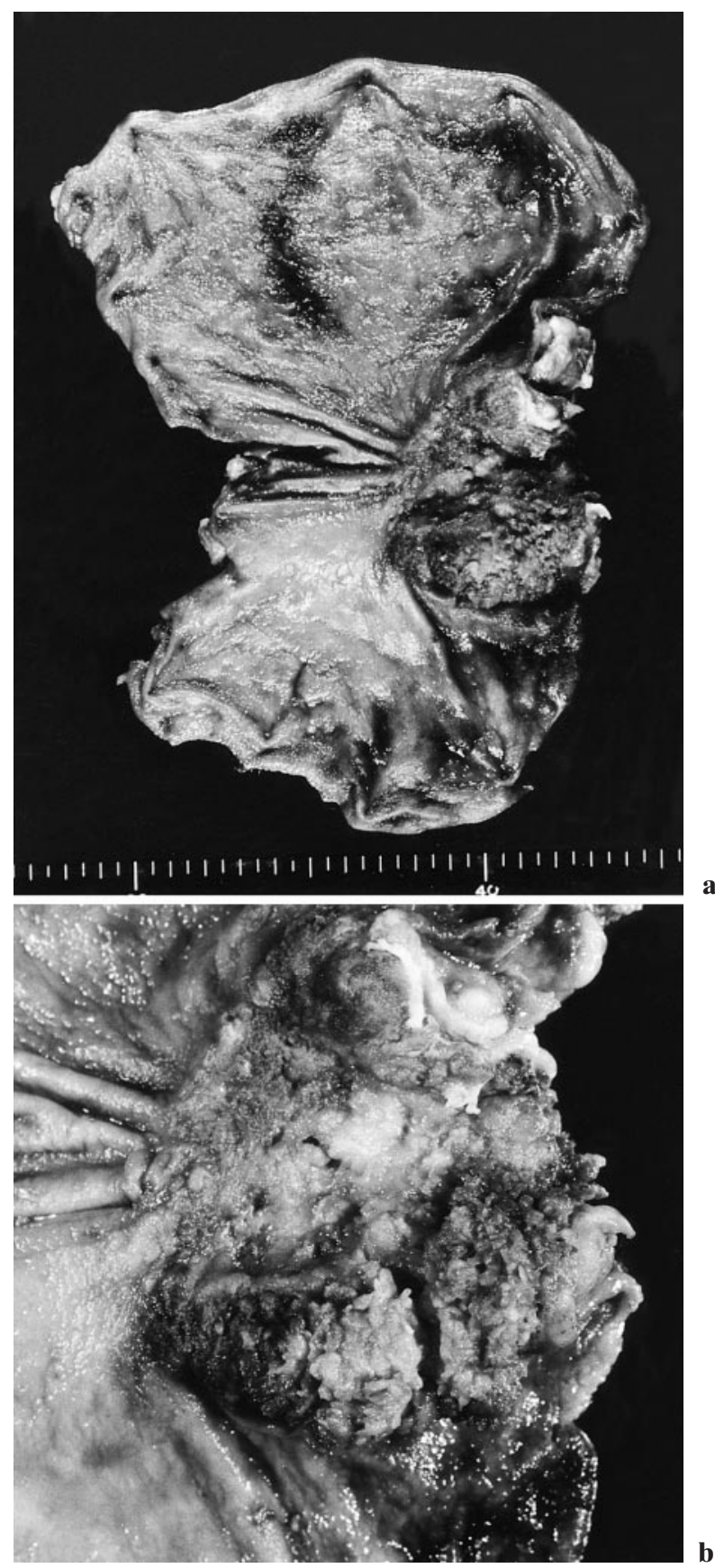

Fig. 5a,b. Photomacrographs of the tumor showing a relaxed stomach, and b cauliflower-type tumor extending over the esophagogastric junction

eventration of the diaphragm is induced by either an idiopathic atrophic change in the diaphragm or by secondary atrophic changes caused by various factors related to neurological dysfunction [3]. The most typical symptom is respiratory insufficiency. Other symptoms may simulate those of large diaphragmatic hernias, with dysphagia, belching, heartburn, and epigastric pain. However, most patients with eventration of the dia- 


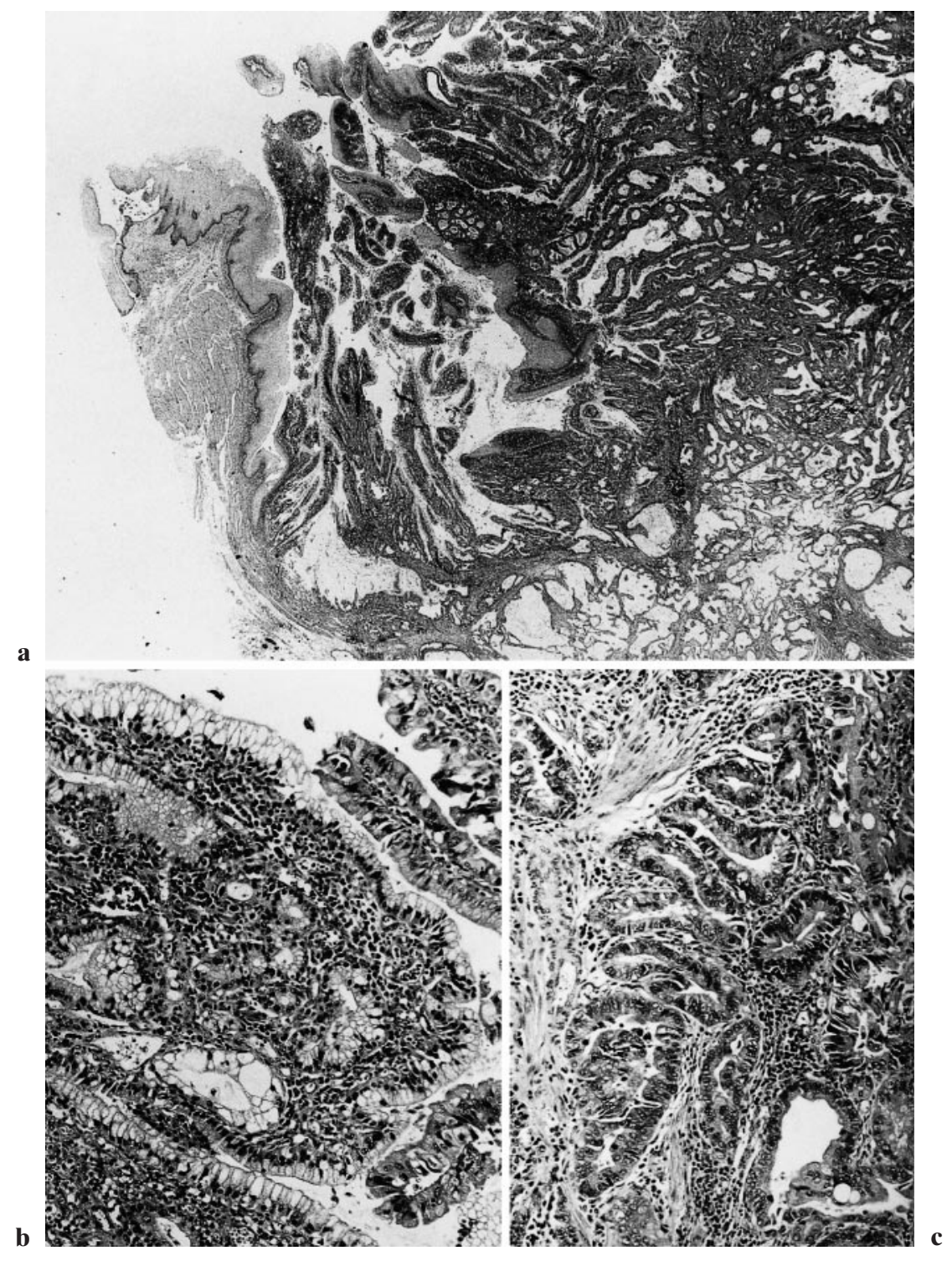

Fig. 6a-c. Photomicrographs of the surgical specimen showing a the sequence of squamous epithelium, columnar epithelium with barrel-shaped cells, dysplasia, and carcinoma $(\mathrm{H} \& \mathrm{E}, \times 25)$. b High-power view of columnar epithelium with barrel-shaped cells and dysplastic epithelium $(\mathrm{H} \& \mathrm{E}, \times 250)$ c with well differentiated adenocarcinoma $(\mathrm{H} \& \mathrm{E}, \times 250)$ phragm are asymptomatic [4]. In our patient, no abnormality of the diaphragm had been observed until she was 44 years of age, and no contributory events had been identified during that period. Based on her clinical course, we inferred that the diaphragmatic eventration was acquired.

Volvulus of the stomach is a well known digestive condition associated with eventration of the diaphragm [5]. In this our patient, however, no volvulus of the stomach was seen, but Barrett's adenocarcinoma was observed. To the best of our knowledge, no previous case of Barrett's adenocarcinoma associated with eventration of the diaphragm has been reported in the literature (MEDLINE search 1966-1997).

In recent years, the incidence of adenocarcinomas of the esophagus and gastric cardia has increased in western countries. Barrett's esophagus has also been noted as a risk factor for these malignancies [6-8]. Barrett's esophagus has generally been defined as a columnar epithelium at least $3 \mathrm{~cm}$ in length above the esophagogastric junction $[9,10]$. However, short-segment Barrett's esophagus (SSBE), which has a columnar epithelium measuring less than $3 \mathrm{~cm}$, is also recognized as Barrett's esophagus [11,12]. SSBE is also considered to be a premalignant condition and there is a wide consensus that most adenocarcinomas of the esophagus and gastric cardia evolve from SSBE [13-15]. On the other hand, it is widely accepted that the genesis of adenocarcinoma arising from Barrett's esophagus is related to the metaplasia-dysplasia-carcinoma sequence [16].

In our patient, we diagnosed the lesion as Barrett's adenocarcinoma arising from SSBE, because: (1) the biopsy specimen from lower esophagus revealed a co- 
lumnar epithelium, (2) the surgical specimen showed a gradual change from squamous epithelium and columnar epithelium to severe dysplasia, and adenocarcinoma was seen on the oral side of the tumor; (3) the gastric mucosa was normal and no intestinal metaplasia was seen; and (4) the columnar epithelium, with goblet cells, dysplastic epithelium, and tumor were all similarly positive for $\mathrm{AB} \mathrm{pH} 2.5[6,17,18]$.

Barrett's esophagus is considered to be an acquired condition caused by hiatal hernia, gastroesophageal reflux, and esophagitis. In patients with SSBE, the typical symptoms are those of gastro-esophageal reflux disease, such as heartburn, regurgitation, and dysphagia. However, about half the patients with SSBE do not have these symptoms $[12,19]$.

In our patient, we assumed that the abnormal relaxation and elevation of the stomach may have induced a pooling of the gastric juice and localized regurgitation at the esophagogastric junction. Subsequently, both esophagitis and SSBE occurred and thereafter Barrett's adenocarcinoma also developed. Interestingly, our patient's surgical specimen showed serial changes from normal squamous epithelium to SSBE, dysplasia, and adenocarcimona during the course of the disease, with the same sequelae as those seen in the metaplasiadysplasia-carcinoma sequence.

In conclusion, to the best of our knowledge, no case of Barrett's adenocarcinoma associated with acquired eventration of the diaphragm has previously been reported in the literature (according to Medline search, 1966-1997). We have reported one such rare case, with a brief literature review. It is possible that the eventration of the diaphragm observed in this patient was complicated not only with volvulus of the stomach but also with SSBE and Barrett's adenocarcinoma.

\section{References}

1. Payne WS, Ellis FH Jr. Esophagus and diaphragmatic hernias. In: Schwartz SI, Shires GT, Spencer FC, Storer EH, editors. Principles of surgery. 4th ed. New York: McGraw Hill 1984; p. 1063-112.

2. McNamara JJ, Paulson DL, Urschel HC Jr, Razzuk MA. Eventration of the diaphragm. Surgery 1968;64:1013-21.
3. Riley EA. Idiopathic diaphragmatic paralysis: A report of eight cases. Am J Med 1962;32:404-16.

4. Pomerantz M. The diaphragm. In: Sabiston DC Jr, Spencer FC, editors. Gibbon's surgery of the chest. 4th ed. Philadelphia: W.B. Saunders; 1983; p. 833-8.

5. Stephenson RH, Hopkins WA. Volvulus of the stomach complicating eventration of the diaphragm. Am J Gastroenterol 1964;41:225-34.

6. Lewin KJ, Appelman HD. Tumors of the esophagus and stomach. Atlas of tumor pathology. Third series, fascicle 18 . Washington DC: American Forces Institute of Pathology, 1996; p. 99-144.

7. Blot WJ, Devesa SS, Kneller RW, Fraumeni JF Jr. Rising incidence of adenocarcinoma of the esophagus and gastric cardia. JAMA 1991;265:1287-9.

8. Pera M, Cameron AJ, Trastek VF, Carpenter HA, Zinsmeister AR. Increasing incidence of adenocarcinoma of the esophagus and esophagogastric junction. Gastroenterology 1993;104:510 3.

9. Herlihy KJ, Orlando RC, Bryson JC, Bozymski EM, Carney CN, Powell DW. Barrett's esophagus: Clinical, endoscopic, histologic, manometric, and electrical potential difference characteristics. Gastroenterology 1984;86:436-43.

10. Endo M. Barrett's esophagus - review of literature (in Japanese, with English abstract). Stomach Intestine 1990;25:391-7.

11. Schnell TG, Sontag S, Chejfec G. Occurrence of adenocarcinoma in short segments or tongues of Barrett's esophagus (abstract). Gastroenterology 1989;96:452.

12. Weston AP, Krmpotich P, Makdisi WF, Cherian R, Dixon A, McGregor DH, et al. Short segment Barrett's esophagus: Clinical and histologic features, associated endoscopic findings, and association with gastric intestinal metaplasia. Am J Gastroenterol 1996;91:981-6.

13. Schnell TG, Sontag SJ, Chejfec G. Adenocarcinomas arising in tongues or short segments of Barrett's esophagus. Dig Dis Sci 1992:37:137-43.

14. Clark GW, Smyrk TC, Burdiles P, Hoeft SF, Peters JH, Kiyabu $\mathrm{M}$, et al. Is Barrett's metaplasia the source of adenocarcinomas of the cardia? Arch Surg 1994;129:609-14.

15. Mendes de Almeida JC, Chaves P, Pereira AD, Altorki NK. Is Barrett's esophagus the precursor of most adenocarcinomas of the esophagus and cardia? A biochemical study. Ann Surg 1997;226:725-33; discussion 733-5.

16. Hamilton SR, Smith RR. The relationship between columnar epithelial dysplasia and invasive adenocarcinoma arising in Barrett's esophagus. Am J Clin Pathol 1987;87:301-12.

17. Weinstein WM, Ippoliti AF. The diagnosis of Barrett's esophagus: Goblets, goblets, goblets. Gastrointest Endosc 1996;44:91-5.

18. Riddell RH. The biopsy diagnosis of gastroesophageal reflux disease, "carditis," and Barrett's esophagus, and sequelae of therapy. Am J Surg Pathol 1996;20 (Suppl 1):S31-50.

19. Spechler SJ, Zeroogian JM, Antonioli DA, Wang HH, Goyal RK. Prevalence of metaplasia at the gastro-oesophageal junction. Lancet 1994;344:1533-6. 